\title{
GUERRA Y MOVILIZACIÓN DE RECURSOS ECONÓMICOS EN EL SIGLO XVIII. UN ENSAYO HISTORIOGRÁFICO
}

\author{
War and the Mobilisation of War Economic Resources \\ in the Eighteenth Century. An Historiographical Essay
}

\author{
Agustín GONZÁLEZ ENCISO \\ Universidad de Navarra \\ agenciso@unav.es
}

Fecha de recepción: 17/12/2019

Fecha de aceptación definitiva: 18/05/2020

RESUMEN: La movilización de recursos para la guerra y sus condiciones es una cuestión importante que no ha empezado a estudiarse en España hasta hace pocos años. En este trabajo se presentan los principales temas que se han investigado, así como las conclusiones más relevantes. El artículo se divide en dos partes. En la primera se analizan las cuestiones dinerarias, en particular, los ingresos fiscales y su empleo en la financiación de la guerra. La segunda parte se dedica a los asentistas que abastecían al rey con productos y servicios diversos. Se trata de saber quiénes eran, cómo trabajaban o qué tipo de beneficios obtenían.

Palabras clave: España siglo XVIII; guerra; empresarios militares; asentistas; Estado contratante; Estado fiscal-militar.

ABSTRACT: The mobilisation of resources to wage war, and its conditions, is quite an important subjet but only a few years ago a sistematic research on that has been done in Spain. This paper is devoted to present the main researched themes, and the most relevant conclusions. The paper is divided in two parts. The first one deals with money, taxes, and the way they were used to finance war. The second part is devoted to contractors supplying the army and navy with different products 
and services. We are interested in knowing who they are, how did they work o what kind of gains they obtained.

Keywords: Eighteenth Century Spain; war; military entrepreneurs; contractors; contractor state; fiscal-military state.

\section{INTRODUCCIÓN}

En el siglo XVIII la guerra se consideraba inevitable, incluso necesaria. Desde luego, la guerra entonces era menos destructiva de lo que fue después y también la vida ofrecía menos expectativas que hoy. Resulta una paradoja, pero incluso la guerra tiene aspectos positivos, como los relacionados con la actividad económica y empresarial. A la hora de hacer la guerra, lo que más les preocupaba a los gobernantes ilustrados era procurarse los recursos necesarios, incluso los objetivos más importantes deben supeditarse a la disponibilidad de recursos y su movilización.

¿Había recursos materiales en España? Uztáriz señala que no puede haber abundancia en un reino, ni ejércitos que lo defiendan, sin un comercio útil y buenas manufacturas, y estas no podrán lograrse sin un adecuado sistema fiscal. Apunta así a la financiación de la guerra por el fisco. En otro momento, el autor indica la necesidad de abastecer a las Fuerzas Armadas y dice que eso es posible hacerlo en España, dada la abundancia de diversos materiales y pertrechos necesarios para hacer la guerra ${ }^{1}$.

Estos párrafos plantean preguntas básicas: ¿cuáles son los recursos necesarios; qué sabemos de ellos para la España del siglo XVIII? Se trata de un problema sustancialmente económico y empresarial, que hasta hace poco no ha comenzado a estudiarse. También hay que movilizar esos medios y hay que asegurarse de que la provisión se encuentre colocada en el lugar y momento necesarios. La dificultad reside en que los ejércitos se mueven y los planes tácticos cambian; por ello, el abastecimiento general previo a que salga una expedición puede resultar inadecuado en el momento de dar la batalla.

En este trabajo haremos un recorrido historiográfico, no exhaustivo, por lo publicado últimamente sobre esta cuestión: la movilización de recursos para la guerra, desde su origen hasta su destino final en el campo de batalla ${ }^{2}$. Nos fijaremos en el dinero y en los materiales y alimentos a proveer: cómo se conseguían, cómo se movilizaban.

1. UzTÁRIZ, Gerónimo de. Theorica y practica de comercio y de marina. Editado por Gabriel Franco. Madrid: Aguilar, 1968, pp. 2 y 215.

2. Bowen, Huw y GonzÁLEZ ENCISO, Agustín (eds.). Mobilising Resources for War: Britain and Spain at Work during the Early Modern Period. Pamplona: Eunsa, 2006. 


\section{EL DINERO}

2.1. Sobre revolución militar y Estado fiscal-militar: el aumento del coste de la guerra

Aunque sea obvio, parece necesario recordar que hacer la guerra exige dinero. En particular, las exigencias dinerarias crecieron mucho durante el siglo XVIII. Dejaremos al margen todas las cuestiones relativas a la revolución militar ${ }^{3}$, no sin insistir en que la guerra no fue solo cada vez más compleja, sino, como nos interesa ahora, más cara ${ }^{4}$. Por otro lado, mayores necesidades militares exigieron, igualmente, más abastecimientos y una logística adecuada. España, que había sido uno de los países pioneros de la revolución militar, vio cómo la guerra volvió a tener protagonismo en el siglo XVIII ${ }^{5}$, y fue siendo cada vez más cara. Conocemos algunos datos de las cantidades que las guerras podían costar, pero no se puede hacer, todavía, un estudio completo ${ }^{6}$; no obstante, hay evidencias de que la provisión para los gastos necesarios fue creciente.

¿Cómo se conseguía el dinero? El protagonismo de los recursos fiscales ha dado lugar a la teoría del Estado fiscal-militar: el aumento de los impuestos para pagar la guerra ${ }^{7}$. A ello se añadiría la centralización administrativa necesaria para gestionar mejor los ingresos, todo lo cual contribuiría a ir construyendo el Estado moderno ${ }^{8}$.

Algunos trabajos estudiaron el aumento de los impuestos a causa de la gue$\mathrm{rra}^{9}$, pero la metodología que implica el concepto de fiscal-military state la aplicó en España Torres Sánchez, quien ha estudiado, primero, el desarrollo de la Tesorería General y la progresiva militarización de sus motivaciones y de sus formas

3. Sobre la revolución militar, ROBERTS, Michael. «The Military Revolution». En RoBERTs, Michael (ed.). Essays in Swedish History. Londres, pp. 195-225; PARKER, Geoffrey. The Military Revolution. Cambridge: Cambridge U. Press, 1988; BLACK, J. A. Military Revolution? Military Change and European Society, 1550-1800. Londres: Macmillan, 1991.

4. Martínez RuIZ, Enrique. Historia militar de la Europa Moderna. Madrid: Síntesis, 2016.

5. Quatrefages, René. La Revolución Militar Moderna. El Crisol Español. Madrid: Ministerio de Defensa, 1996; MARTínez RuIz, Enrique. Los soldados del rey. Los ejércitos de la monarquía bispánica (1480-1700). Madrid: Actas, 2008.

6. GONZÁLEZ ENCISO, Agustín. War, Power and the Economy. Mercantilism and State Formation in 18th-Century Europe. Londres: Routledge, 2017, pp. 134 y ss.

7. BREWER, John. The Sinews of Power. War, Money and the English State, 1688-1783. Londres: Unwin Hyman; GLETE, John. War and the State in Early Modern Europe: Spain, the Dutch Republic and Sweden as Fiscal-Military States, 1500-1650. Londres, 2002. La bibliografía sobre el fiscal-military state es ya abundante.

8. Torres SÁNCHEZ, Rafael (ed.). War, State and Development. Fiscal-military States in the Eighteenth Century. Pamplona: Eunsa, 2007; STORRs, Christopher. The Fiscal-military State in Eighteenth Century Europe. Farnham: Ashgate, 2008.

9. Barbier, J. A. y Klein, H. S. "Las prioridades de un monarca ilustrado: el gasto público bajo el reinado de Carlos III. Revista de Historia Económica, 1985, 3, pp. 473-495. JuRADO SÁNCHEZ, José. El gasto de la Hacienda española durante el siglo XVIII. Cuantía y estructura de los pagos del Estado (1703-1800). Madrid: Instituto de Estudios Fiscales, 2006. 
organizativas; luego el Estado fiscal-militar de Carlos III. Una obra de síntesis suya tiene también un importante valor de historia comparada ${ }^{10}$. Las tesorerías militares cuentan igualmente con estudios de Solbes Ferri ${ }^{11}$; es importante la reciente aportación de Dubet y Solbes Ferri sobre el Tesorero General ${ }^{12}$.

España no aparece como un Estado fiscal-militar puro, según el modelo inglés. La mayor diferencia está en que España no "maximizó», por así decir, el aumento de los ingresos, ni priorizó la guerra por motivos económicos. Tampoco se endeudó durante mucho tiempo. Desde estos puntos de vista, España sería un Estado fiscal-militar más limitado. En todo caso, se buscó aumentar los ingresos fiscales por las necesidades de la guerra y también hubo una centralización administrativa en la gestión del dinero para la guerra; por lo tanto, sí se dio una relación entre guerra y aumento fiscal.

\subsection{Las fuentes de financiación de la guerra en España: los ingresos fiscales ordinarios}

La principal fuente de financiación fueron los impuestos ordinarios, de los que salía el gasto básico. Tenemos un conocimiento bastante completo de los impuestos ordinarios del siglo XVIII, aunque no abunda la bibliografía ${ }^{13}$. Hay estudios sobre impuestos concretos, pero solo desde una perspectiva fiscal. Veremos solamente lo que tiene relación directa con la guerra.

¿Cómo se utilizaron los ingresos fiscales ordinarios para pagar las guerras? Las rentas provinciales castellanas ${ }^{14}$ eran las que más aportaban al erario. Pero su valor estuvo estancado hasta 1740 por la política del alivio fiscal ${ }^{15}$. El Gobierno

10. TORRES SÁNCHEZ, Rafael. La llave de todos los tesoros. La Tesorería General de Carlos III. Madrid: Sílex, 2012; El precio de la guerra. El Estado fiscal-militar de Carlos III (1779-1783). Madrid: Marcial Pons, 2013; Constructing a Fiscal-military State in Eighteenth Century Spain. Basingstoke: Palgrave, 2015.

11. SOlBES FerRI, Sergio. "Tesorerías de Ejército: estructuras administrativo-contables para la gestión de los recursos fiscales en la España borbónica. Galicia, 1765-1780». Obradoiro de Historia Moderna, 2007, 16, pp. 197-211; "El control del gasto de la Marina española en las Secretarías de Estado y del Despacho. Los pagos dependientes de la Tesorería General en la primera mitad del siglo XVIII". En BAudot, María (ed.). El Estado en guerra. Expediciones navales españolas en el siglo XVIII. Madrid: Polifemo, 2014, pp. 147-194.

12. Dubet, Anne y SOlBes FerRi, Sergio. El rey, el ministro y el tesorero. El gobierno de la Real Hacienda en el siglo XVIII español. Madrid: Marcial Pons, 2019.

13. Artola, Miguel. La Hacienda del Antiguo Régimen. Madrid: Alianza, 1982; Merino NAVArro, J. P. Las cuentas de la Administración central española, 1750-1820. Madrid: Instituto de Estudios Fiscales, 1987; La Hacienda de Carlos IV. Madrid: Rh+ Ediciones, 2014; TorRes SÁNCHEZ, Rafael. Constructing a Fiscal-military State in Eighteenth Century Spain. Basingstoke: Palgrave, 2015.

14. Angulo Teja, Carmen. La Hacienda española en el siglo XVIII. Las rentas provinciales. Madrid: Centro de Estudios Políticos y Constitucionales, 2002.

15. FernándeZ Albaladejo, Pablo. «El decreto de suspensión de pagos de 1739: análisis e implicaciones». Moneda y Crédito, 1977, 142, pp. 51-81; GonZÁlez EnCISO, Agustín. "A Moderate and Rational 
pudo apoyarse en sus equivalentes, cobrados en la Corona de Aragón desde la guerra de Sucesión, para pagar los gastos de las tropas establecidas en Cataluña y Valencia, desde donde salieron las expediciones a Italia y Orán en 1717-1719, 1732 y $1734^{16}$. Más tarde, la Administración usaría las rentas provinciales para aumentar tarifas o cobrar por nuevos conceptos para financiar otros conflictos $(1741,1779)^{17}$. Las rentas provinciales serían objeto de dos reformas, una intentada, la otra conseguida. La única contribución no se llegó a establecer por motivos solamente políticos ${ }^{18}$, sino por razones técnicas ${ }^{19}$. El impuesto sí sería modificado de manera importante por Lerena, en 1785, para amortizar los gastos de la guerra contra Gran Bretaña. Cabe resaltar que las dos medidas mencionadas se pensaron o tomaron después de dos grandes conflictos.

Las rentas generales, aduanas, tenían un rendimiento menor ${ }^{20}$. Dependían de un comercio que no era tan abundante como se deseaba; de unas tarifas poco proteccionistas, y de unas coyunturas cambiantes, bajas durante los conflictos. Aunque el pensamiento ilustrado daba mucha importancia al comercio exterior, los gobernantes españoles no hicieron una modificación sustancial hasta 1776-1778: la reforma del libre comercio con América a la que se sumaron aranceles proteccionistas en 1782. La medida provocó un alza importante del tráfico y de los ingresos aduaneros ${ }^{21}$. Sus resultados se utilizarían para pagar las deudas de la guerra con Gran Bretaña.

Absolutism. Spanish Fiscal Policy in the First Half of the Eighteenth Century». En TORRES SÁNCHEZ, Rafael (ed.). War, State and Development: Fiscal-military States in the Eighteenth Century. Pamplona: Eunsa, 2007, pp. 109-132.

16. MARTí, Eduard. "Cataluña y la movilización de recursos militares para la expedición a Sicilia de 1718”. En Congreso Internacional Renovary Difundir la Historia Militar. Madrid; Casa de Velázquez y UNED, 27-29 de septiembre de 2017. MARTín CORRALES, Eloy. "Cataluña era una fiesta. Las celebraciones por la toma de Orán». En Bunes IBARRA, Miguel Ángel y Alonso AcERO, Beatriz (coords.). Orán: bistoria de la corte chica. Madrid: Polifemo, 2011, pp. 119-142; FÉ CANTÓ, Luis Fernando. «El desembarco en Orán en 1732. Aproximación analítica a una operación compleja». Revista Universitaria de Historia Militar, 2016, 5, 10, pp. 89-110.

17. Marina Barba, J. "La contribución extraordinaria del diez por ciento de las rentas de 1741". Chronica Nova, 1993, 21, pp. 279-355; TORRES SÁnCHEZ, Rafael. El precio de la guerra. Cap. II.

18. MELón JiménEZ, Miguel Ángel. «Las rentas provinciales y la idea de una sola contribución real de Miguel Zavala y Auñón». En Pereira Iglesias, José Luis (ed.). Felipe V de Borbón, 1701-1746. Actas del Congreso de San Fernando, Cádiz, 27 de noviembre a 1 de diciembre de 2000. San Fernando-Córdoba: Fundación Municipal de Cultura-Universidad de Córdoba, 2002, pp. 61-90; Castellano, Juan Luis. Gobierno y poder en la España del siglo XVIII. Granada: Universidad de Granada, 2006.

19. Angulo Teja, Carmen. La Hacienda española en el siglo XVIII.

20. Melón Jiménez, Miguel Ángel. «Las fronteras de España en el siglo XVIII: algunas consideraciones". Obradoiro de Historia Moderna, 2010, 19, pp. 161-186.

21. FISHER, John. Commercial Relations between Spain and Spanish America in the Era of Free Trade, 1778-1796. Liverpool, 1985; GARCía BAQUERO, Antonio. «El comercio colonial en el cambio de siglo: De la apertura a la quiebra del sistema monopolístico español». En Morales Moya, Antonio (coord.). 1802. España entre dos siglos y la recuperación de Menorca. Madrid: Sociedad Estatal de Conmemoraciones Culturales, 2003; ENCISO RECIO, Luis Miguel. «El fin del gran tráfico atlántico español». En 
La renta fiscal que más se dedicó a la guerra, y al mundo militar y naval, fue la del tabaco ${ }^{22}$. Conocemos los ingresos útiles de la renta y la parte que cada administración del tabaco dedicaba a pagar gastos militares o navales, al entregar sus productos líquidos en las correspondientes tesorerías de ejército o de marina ${ }^{23}$. Además, sabemos que en algunos conflictos (1733-1737, 1741, 1779 y 1794), el precio de las labores se elevó sustancialmente -y también los ingresos-, aunque fuera a costa del consumo oficial.

Finalmente, es preciso hacer mención del impuesto que el Estado cobraba por la minería de los metales americanos. Durante el siglo XVIII, aun con oscilaciones, los ingresos por metales preciosos americanos crecieron ${ }^{24}$. Ese ingreso desempeñaba el papel de equilibrador del presupuesto. En tiempos de paz, el presupuesto ordinario no bastaba para los gastos ordinarios y se formaba un déficit que se saldaba con las remesas de los metales americanos ${ }^{25}$. En tiempos de guerra había que esperar a la paz para que las remesas llegaran. Ese aspecto positivo pudo tener una contrapartida: si el metal suplía cada déficit anual, podía justificar a los gobernantes para eludir la reforma fiscal. El metal americano pudo cubrir los déficits hasta los años setenta; pero después, aunque la cantidad de metales aumentó, las necesidades lo hicieron mucho más.

En el último tercio del siglo la defensa de América se hizo más urgente. Hasta entonces América casi se había podido defender a sí misma, pero la pérdida de La Habana en 1762 actuó como un revulsivo. En el terreno fiscal y defensivo esta situación traería consecuencias, pues los problemas se «imperializaban». Un resultado fue el establecimiento de los estancos del tabaco en territorios americanos en la segunda mitad del siglo (Perú, en 1752; luego se sumarían Chile y La Plata en 1753; México, 1764; Venezuela y otros territorios, en 1778, y Filipinas y Puerto Rico en 1782 y 1783) ${ }^{26}$. El tabaco empezaría a tener un valor fiscal mucho mayor. Por ejemplo, en la relación de los ramos fiscales de Revillagigedo para Nueva España,

AlCALÁ-ZAMORA, José (coord.). La España oceánica de los siglos modernos y el tesoro submarino español. Madrid: Real Academia de la Historia y Marquesa Viuda de Arriluce de Ybarra, 2008, pp. 253-312.

22. GonZález EnCISO, Agustín. «Tabaco y Hacienda, 1670-1840». En Alonso, Luis; GálveZ MuÑOZ, Lina y De LuxÁn, Santiago (eds.). Tabaco e historia económica. Madrid: Fundación Altadis, 2006, pp. 43-69.

23. Rodríguez Gordillo, José Manuel y GÁrate Ojanguren, M. Montserrat (eds.). El monopolio español de tabacos en el siglo XVIII. Consumos y valores: una perspectiva regional. Madrid: Fundación Altadis, 2007.

24. García-Baquero González, Antonio. El comercio colonial en la época del absolutismo ilustrado. Problemas y debates. Granada: Universidad de Granada, 2003.

25. TORRES SÁNCHEZ, Rafael. "Public Finances and Tobacco in Spain for the American War of Independence». En Bowen, Huw y GonzÁlez EnCISO, Agustín (eds.). Mobilising Resources for War. 2006, pp. 191-224.

26. Deans-Smith, Susan. "The Money Plant: The Royal Tobacco Monopoly of New Spain, 1765-1821». En Jacobsen, Nils y PuHle, Hans-Jürgen (eds.). The Economies of New Mexico and Peru During the Late Colonial Period, 1760-1810. Berlín: Colloquium Verlag, 1986, pp. 361-87; DE LuXÁN, Santiago (dir.). Política y hacienda del tabaco en los imperios ibéricos (siglos XVII-XIX). Madrid: Centro de Estudios Políticos y Constitucionales, 2014. 
en 1751, no aparece el tabaco ${ }^{27}$; su valor estaba oculto en el ramo de alcabalas. Los saldos fiscales positivos de la renta se enviaron a España, al menos los de Perú y Nueva España ${ }^{28}$, pero el tabaco del estanco americano fue un ingreso a tener en cuenta para pagar los gastos de defensa del imperio.

El otro producto que se imperializa, en la segunda mitad del siglo, es el metal precioso, pues sus beneficios se repartieron por más territorios americanos al extenderse la práctica del situado ${ }^{29}$.

\subsection{Ingresos extraordinarios y deuda}

Los ingresos ordinarios siempre eran insuficientes para librar cualquier contienda, era necesaria una fiscalidad extraordinaria. Contamos con algunos trabajos que han explicado la financiación, o parte de ella, de algunas guerras en concreto. Interesan, al respecto, los trabajos que estudian la financiación de la guerra de Sucesión $^{30}$, de la conquista de Nápoles en $1734^{31}$, de la guerra de la Oreja de Jenkins $^{32}$, de la invasión de Portugal en $1762^{33}$, de la guerra con Inglaterra en $1780^{34}$ o de la guerra de la Convención ${ }^{35}$. De estos estudios se desprenden, de modo general, algunas conclusiones sobre las medidas extraordinarias tomadas en caso de guerra, que cabe enumerar, sin orden de prelación: aumento en las tarifas de

27. SÁnCHez SANTIRÓ, Ernest. Corte de Caja. La Real Hacienda de Nueva España y el primer reformismo fiscal de los Borbones (1720-1755). Alcances y contradicciones. México, 2013, p. 127.

28. KLEIN, Herbert. Las finanzas americanas del imperio español, 1680-1809. México: Instituto Mora y U. Autónoma de México, 1994, pp. 44, 106.

29. MARICHAL, Carlos. La bancarrota del virreinato. Nueva España y las finanzas del imperio español, 1780-1850. México: Fondo de Cultura Económica, 1999; MARICHAL, Carlos y VON GrAFENSTEIN, Johana (coords.). El secreto del imperio español: los situados coloniales en el siglo XVIII. México: Colmex e Instituto Mora, 2012.

30. KAMEN, Henry. La Guerra de Sucesión en España, 1700-1715. Barcelona: Grijalbo, 1974; SANZ AYÁN, Carmen. "Administration and Resources for the Mainland War in the First Phases of the War of the Spanish Succession». En Bowen, Huw y González Enciso, Agustín (eds.). Mobilising Resources for War, pp. 135-158; "Causas y consecuencias económicas de la Guerra de Sucesión Española». Boletín de la Real Academia de la Historia, 2013, CCX-II, pp. 187-226.

31. GONZÁLEZ ENCISO, Agustín. "Pagar la batalla. Campillo y el dinero para el ejército de Nápoles y Lombardía, 1734-1736». Memoria y Civilización, 2020, 23, pp. 1-30. Se presentó un avance en Congreso Internacional: Renovary difundir la Historia Militar. La batalla como protagonista de la historia, Segovia, 27-28 de septiembre de 2018.

32. FernándeZ de Pinedo EChevarría, Nadia. "Jenkins Ear and Tax Collection in Spain in the 18th Century». Presentado en XV International Economic History Congress, Utrecht, 2009; MARINA BARBA, J. "La contribución extraordinaria del diez por ciento de las rentas de 1741". Chronica Nova, 1993-1994, 21, pp. 279-355.

33. GonZÁlez ENCISO, Agustín. "Spain's Mobilisation of Resources for the War with Portugal in 1762». En Bowen, Huw y GonzÁlez Enciso, Agustín (eds.). Mobilising Resources for War, pp. 159-190.

34. TORRES SÁNCHEZ, Rafael. El precio de la guerra.

35. Artola, Miguel. La Hacienda del Antiguo Régimen, pp. 404-412. 
impuestos existentes, creación de nuevos impuestos -sobre todo sisas-, donativos -voluntarios o forzosos-, confiscaciones temporales, etc. Lo característico del caso español, en comparación con otros países, es que en España la fiscalidad extraordinaria de guerra desaparecía con la llegada de la paz ${ }^{36}$.

La guerra se financió también con deuda. Otros países se endeudaron mucho para poder afrontar los gastos de guerra. España lo había hecho, de manera habitual, en los siglos anteriores -los juros-, pero no lo hizo en el XVIII, o lo hizo tarde. Los monarcas anteriores a Carlos III deploraron la deuda y siguieron una política de desendeudamiento: había que terminar con el pago de sus intereses. Por otro lado, Carlos III se embarcó en algunas actividades de deuda con la voluntad de que fueran temporales ${ }^{37}$. También es cierto que, finalmente, Carlos III creó los vales reales y el Banco de San Carlos, un instrumento para la deuda pública ${ }^{38}$. Esto demuestra que a partir de entonces consideró oportuno entrar por la vía del papel moneda. Más tarde la realidad se fue imponiendo y en su reinado, primero, y más en el de Carlos IV, volvieron los préstamos pedidos a banqueros extranjeros, particularmente a holandeses ${ }^{39}$.

Todas estas medidas tienen que ver con la guerra o se toman a pesar de ella. La de Sucesión exigió una larga serie de medidas extraordinarias ${ }^{40}$. Por lo demás, parte de la financiación de la guerra vino gracias a la rebaja de la deuda de juros, que liberaba una porción de los ingresos fiscales ordinarios. El desendeudamiento de Felipe V se enfrentó a sus deseos revisionistas. La participación en la guerra de Sucesión de Polonia, que llevó a la conquista de Nápoles, se pagó con metales de América, con el aumento del precio del tabaco ${ }^{41}$, y con empréstitos a corto plazo. La dificultad de pagar algunos de estos préstamos se descubriría en la crisis de $1739^{42}$. La guerra de la Oreja de Jenkins se volvió a pagar con metales, con tabaco (aumento del precio de las labores) y con lo ahorrado en la suspensión de pagos de 1739, aunque también se tomaron medidas extraordinarias ${ }^{43}$. Por su parte, Fernando VI se benefició de la administración directa, que permitió ingresar lo

36. González Enciso, Agustín. War, Power and the Economy, pp. 126 y ss.

37. Torres SÁnchez, Rafael. El precio de la guerra. Felipe V siguió la política del «alivio de los vasallos» recomendada por Felipe IV a Carlos II en su testamento. SÁnCHEZ BeLéN, Juan. La política fiscal de Castilla durante el reinado de Carlos II. Madrid: Siglo XXI, 1996.

38. Tedde De LorCa, Pedro. El Banco de San Carlos (1782-1829). Madrid: Alianza, 1988.

39. Merino Navarro, J. P. La Hacienda de Carlos IV.

40. KAMEN, Henry. La Guerra de Sucesión.

41. Pulido Bueno, Ignacio. José Patiño. El inicio del gobierno político-económico ilustrado en España. Huelva, 1998.

42. Dubet, Anne. "La suspensión de pagos de 1739: ¿una medida de "buen gobierno" de la Hacienda?». Espacio, Tiempo y Forma, 2017, 30, pp. 19-56.

43. González EnCiso, Agustín. "La Guerra de la Oreja de Jenkins. Política y economía». En DíAz Benítez, Juan José; Galván Rodríguez, Eduardo y de LuXÁn MELÉndez, Santiago (eds.). Conflictos bélicos y relaciones internacionales (1739-1927). Tenerife: Ediciones Idea, 2011, pp. 27-87. 
que dejaron de ganar los arrendatarios ${ }^{44}$; también prefirió mantener una posición pacifista que le permitiera preparar el futuro ${ }^{45}$. El beneficiado sería su hermano Carlos III, quien pudo invadir Portugal en 1762 con el dinero contante y sonante, encerrado en el cuarto del tesoro, que Fernando había ahorrado ${ }^{46}$.

De todos modos, decir que los monarcas no se endeudaban es inexacto. Todos los acontecimientos bélicos, incluido el más peculiar de Portugal, se beneficiaban, entre otras cosas, de los préstamos que suponían los abastos pagados por los asentistas quienes, en caso de guerra, eran apremiados a proveer urgentemente lo necesario. El rey disponía de los materiales, pero el pago de esos servicios se haría mucho más tarde. La guerra se hace con impagos que, en la práctica, son préstamos sin intereses, pues el asentista recibirá más tarde solamente lo debido por el precio de su provisión.

La guerra contra Gran Bretaña, en 1779, forzó a tomar medidas muy renovadoras -vales, banco, reforma de las alcabalas...-, con las que se pudo acabar pagando todo, contando con los beneficios del comercio libre con América, establecido ya en $1778^{47}$. Fue la guerra contra la Convención, en 1794, la que puso contra las cuerdas el sistema fiscal y de deuda de la monarquía. El proceso inflacionario ${ }^{48}$, en parte causado por la guerra, reducía el valor de los ingresos fiscales ordinarios; a su vez, los costes de la guerra aumentaron exponencialmente. En ese ambiente, la solución fue aumentar la emisión de vales reales. Pero, al fallar la base fiscal -los ingresos ordinarios, que deberían haber asegurado el pago de los intereses y, por lo tanto, la confiabilidad de los vales-, estos se depreciaron, lo cual vino a dar al traste con el sistema, incapaz de atender todas las necesidades ${ }^{49}$.

\section{ABASTECIMIENTOS Y SUMINISTROS}

Aparte de las cuestiones dinerarias, la guerra supuso una amplia demanda de bienes y servicios, muy variados, necesarios para poder dar la batalla con garantía de éxito. Desde esa perspectiva, parece claro que la guerra influyó positivamente en los sectores sobre los que ejerció su demanda ${ }^{50}$. El abastecimiento benefició,

44. GonZÁlez ENCISO, Agustín. «Between Private and Public Interests: the Moral Economy of Collaboration in Eighteenth-century Spain». En Felix, Joël y Dubet, Anne (eds.). The War Within. Private Interests and the Fiscal State in Early-Modern Europe. Cham (Suiza): Palgrave-Macmillan, 2018, pp. $171-194$.

45. Gómez URdáñez, José Luis. El proyecto reformista de Ensenada. Lérida: Milenio, 1996.

46. Barbier, J. A. "Towards a New Chronology for Bourbon Colonialism: The "Depositaría de Indias" of Cadiz, 1722-1789". Ibero-AmeriKanisches Archiv, 1980, 6, 4, pp. 341-342.

47. Enciso Recio, L. M. «El fin del gran tráfico atlántico español».

48. Hamilton, Earl J. Guerra y precios en España, 1651-1800. Madrid: Alianza, 1988.

49. Un buen resumen en ARTOLA, Miguel. La Hacienda del Antiguo Régimen, pp. 383-435.

50. Bowen, H. V. War and British Society, 1688-1815. Cambridge: Cambridge U. P., 1998. 
particularmente, a altos financieros y empresarios encargados de abastecer las necesidades militares ${ }^{51}$, también a una amplia gama de instituciones -gremios, ayuntamientos, conventos...- y personas concretas, de todo el arco social, que pudieron ofrecer sus trabajos para las Fuerzas Armadas. Se trata de los llamados empresarios militares, los protagonistas del contractor state ${ }^{52}$.

\subsection{Las formas del Estado contratante (contractor state): comprar o fabricar}

Todos los Estados tuvieron que contratar bienes y servicios de particulares para su abastecimiento; la Administración pública no era capaz de cubrir sus necesidades, por sí sola, sin el recurso a los particulares. Ello implica que el concepto de contractor state hay que enfocarlo desde la colaboración público-privado, una colaboración que la historiografía no ha puesto claramente de manifiesto. La expresión público-privado expresa una dualidad que en el siglo XVIII estaba menos marcada que en tiempos posteriores. Dicho esto, una de las primeras cuestiones a dilucidar es la decisión del Estado de comprar o fabricar, de recurrir al ámbito particular o cubrir los servicios por administración ${ }^{53}$. En la España del siglo XVIII dominó el recurso a los particulares ${ }^{54}$, que había sido el modo habitual de operar; en todo caso, durante el reinado de Carlos III hubo un giro hacia la administración directa en la fabricación de algunos productos estratégicos, como cañones y, eventualmente, barcos 55 .

Probablemente, no hay un sistema decidido de antemano que determinara la elección de una forma u otra. El Estado buscaba la eficiencia y poder tener el producto deseado en el lugar y momento oportunos, al mejor precio. El recurso a los asentistas no es una muestra de debilidad del Estado -como pudo haberse considerado para algunos momentos del siglo XVII-, sino el medio que los gobernantes consideraron más adecuado para conseguir sus fines. En el giro estatalista

51. TORRES SÁNCHEZ, Rafael. Military Entrepreneurs and the Spanish Contractor State in the Egibteenth Century. Oxford: Oxford U. P., 2016.

52. Bowen, H. V. et al. "Forum: The Contractor State, c. 1650-1815". International Journal of Maritime History, 2013, XXV, 1, pp. 239-274.

53. Thompson, I. A. A. War and Government in Habsburg Spain, 1560-1620. Londres: The Athlone Press, 1976; TorRes SÁnchez, Rafael. "Producir o comprar. La demanda de la Corona española de productos industriales en el siglo XVIII». En Ribot García, Luis y De Rosa, Luigi (eds.). Industria y Época Moderna. Madrid: Actas e Istituto Italiano per gli Studi Filosoficci, 2000, pp. 95-131.

54. TORRES SÁNCHEZ, Rafael. Military Entrepreneurs, p. 18.

55. AlCalá-Zamora, José. Liérganes y la Cavada. Historia de los primeros altos hornos españoles (1622-1834). Santander: Estudio, 2004; VAldez-Bubnov, Iván. Poder naval y modernización del Estado: política de construcción naval española (siglos XVI-XVIII). México: Universidad Autónoma, 2011, y «Shipbuilding administration under the Spanish Habsburg and Bourbon regimes (1590-1834): A comparative perspective». Business History, 2018, 60, 1, pp. 105-125; GONZÁLEZ ENCISO, Agustín (ed.). Un Estado militar: España, 1650-1820. Madrid: Actas, 2012, y "War contracting and artillery production in Spain». Business History, 2018, Business pp. 87-104. 
de Carlos III, que es solo parcial, jugaron también factores ideológicos -respecto al papel estratégico de cañones y barcos-, como de calidad y necesidad de modernización tecnológica ${ }^{56}$. Que se consiguieran los resultados deseados, o no, es otro tema.

Por otra parte, respecto a la contratación con los asentistas, sería preciso señalar cuáles fueron los modos elegidos. Hay dos modos generales, que pueden abarcar variaciones: comprar en el mercado abierto -como podría hacerlo cualquier particular- o conceder un privilegio exclusivo, un monopolio de facto. El Estado español rara vez recurría a un mercado abierto, salvo por razones de urgencia, sino que contrataba con un asentista concreto, entendiendo aquí el término asentista de manera general: cualquier persona o institución. Si se trataba de asientos firmados, normalmente eran contratos de larga duración -entre tres y diez años-, por lo que el asentista disfrutaba de un monopolio durante el período de contrato. Cuando surgían urgencias en los lugares donde estaba acantonado el ejército o cerca de los puertos desde donde debía partir una expedición marítima, se recurría a asentistas eventuales, a contratas específicas con productores locales que completaban lo que se necesitara en última instancia.

Si, por un lado, el Estado recurría a la contratación particular y, por otro lado, las necesidades eran abundantes, variadas y, a la vez, cambiantes en el tiempo, hemos de reconocer que el Estado tenía necesidad de relacionarse con una gama muy amplia de personas e instituciones. A todos los podemos llamar asentistas. Unos lo serían solamente de forma eventual, otros, en cambio, lograrían una relación más larga y asegurarían un negocio nada desdeñable, aunque tuviera sus riesgos. A continuación, haremos una clasificación de los asentistas según su tipología empresarial o social, lo cual a veces también está relacionado con el tipo de producto que suministraban.

Se trata de una clasificación posible, es decir, cabrían otras formas de hacerlo; esta nos ha parecido adecuada porque se centra en lo que son la mayoría de los asentistas, empresarios. Como tales, buscan su oportunidad de negocio, discuten los precios, se relacionan con los colaboradores oportunos, intentan superar a la competencia, etc. Son profesionales que conocen los productos con los que trabajan y sus mercados, los sistemas de producción y los tráficos de distribución. No trabajan solos, sino que forman compañías más o menos estables, grandes o pequeñas. Si son grandes negociantes, trabajan con personas que les consiguen los productos locales cuya distribución ellos coordinan. En realidad, hablar de asentistas, de contratistas de suministros militares, es hablar de historia empresarial,

56. Helguera QujJada, Juan. «De La Cavada a Trubia. Intervencionismo estatal y cambio tecnológico en las fundiciones de artillería del norte de España (1760-1800)». En OCAMPO SuÁrEZ-VALDÉs, Joaquín (ed.). Empresa y empresarios en el norte de España (siglo XVIII). Oviedo: Trea, 2012, pp. 153-182; GONZÁLEZ ENCISO, Agustín. «Del contractor state al Estado fabricante. El cambio de propiedad en la fábrica de municiones de Eugui». Revista de Historia de la Economía y de la Empresa, 2013, VII, pp. $455-484$. 
un aspecto de la historia empresarial que ha quedado oculto en los manuales al uso de la historia de la empresa, de ahí la necesidad de recuperarlos; y también, si fuera el caso, de reinterpretarlos ${ }^{57}$.

Es una categoría que es necesario resaltar porque tiene características propias. En la Edad Moderna, el Estado es el mayor demandante. Atender a las necesidades del ejército o de la marina equivaldría a atender las necesidades de una gran ciudad. Estamos hablando de ejércitos de entre 20.000 y 100.000 hombres, aproximadamente, cifras muy superiores a las que tenían la mayoría de las ciudades de la época. Además, está la movilidad, lo que obliga a unos problemas logísticos de envergadura y a variar las fuentes del abastecimiento, problemas diferentes también a los que plantea una ciudad. En el caso de la marina había que calcular provisión para el mantenimiento de varios meses, pues no era fácil que los barcos pudieran repostar antes de ese tiempo. En definitiva, los asentistas debían enfrentarse a retos de notable complejidad empresarial, superior a los que podrían afrontar en mercados y con demandas ordinarias.

\subsection{Los hombres de negocios, las grandes corporaciones y las compañías de comercio}

El primer grupo de asentistas que encontramos es el de los hombres de negocios y financieros. El término hombre de negocios se refiere a personas cuya dedicación económica está relacionada, principalmente, con el movimiento de capitales; eran capaces de mover fuertes sumas, en particular en su negociación con el Estado. Comercian, pero no son propiamente comerciantes, hacen mucho más. Se les podría llamar financieros, pero cabe el riesgo de interpretar que eran solamente banqueros o prestamistas; eran eso, pero mucho más. Su negocio más característico fue el de arrendatarios de impuestos, una posibilidad que en España terminó, definitivamente, en 1749. Solían complementar este negocio con asientos.

Compaginar esas dos actividades era normal y, hasta cierto punto, necesario. Los asientos podían acarrear problemas si el monarca pagaba tarde, como era previsible; en ese caso, el arrendamiento de impuestos suponía una posibilidad de resarcirse que no complicaba las cosas a la Administración pública. Por otra parte, el arrendamiento de impuestos era un buen camino para afirmar una posición de influencia en la corte o aumentar luego los negocios con algún asiento.

57. Torres SÁnCHEZ, Rafael. "Administración o asiento. La política estatal de suministros militares en la Monarquía española del siglo XVIII. Studia Historica. Historia Moderna, 2013, 35, pp. 159-199; 't HART, Marjolein; BRANDON, Pepijn y TORRES-SÁNCHEZ, Rafael. «Introduction: maximising revenues, minimising political costs-challenges in the history of public finance of the early modern period». Financial History Review, 2018, 25.1, pp. 1-18. 
En la primera mitad del siglo XVIII hubo no pocos de estos hombres de negocios, muchos de ellos navarros. Es el caso de los Goyeneche ${ }^{58}$, Aldaz ${ }^{59}$, Arizcun ${ }^{60}$, Mendinueta ${ }^{61}$, Astrearena; pero también de otros lugares: Valdeolmos, el marqués de Santiago ${ }^{62}$, Isla ${ }^{63}$, por ejemplo. La historia de cada uno de ellos difiere. En unos casos partieron del pequeño comercio y fueron ascendiendo (Mendinueta); en otros, su calidad de hidalgos les permitió un temprano acceso a la corte, la compra de algún oficio, y de ahí a las posibilidades que esa influencia pudiera ofrecer (Goyeneche, Isla); otras veces eran la segunda generación de comerciantes, que vieron la oportunidad en los negocios de la corte (Valdeolmos, Aldaz).

En la segunda mitad del siglo, sin arrendamientos de impuestos, hubo que buscar otras vías de acceso a las oportunidades de la corte. Algunos pudieron seguir aprovechándose de las influencias anteriores; para otros, el salto a los grandes negocios con el rey, y el logro de asientos, vino desde el comercio. Entre todos estos podemos recordar a Aragorri, St. Aulari ${ }^{64}$, Partearroyo, Hormazas, Garro, Raimundo Ibáñez ${ }^{65}$.

Tanto los de la primera mitad como los de la segunda se caracterizan por que consiguieron disfrutar de uno o varios asientos durante bastante tiempo, algunos

58. AQUERRETA, Santiago. Negocios y finanzas en el siglo XVIII: la familia Goyeneche. Pamplona: Eunsa, 2000; ANDúJAR CASTillo, Francisco. «Juan de Goyeneche. Financiero, tesorero de la reina y mediador en la venta de cargos». En GonzálEz EnCiso, Agustín (ed.). Navarros en la Monarquía española en el siglo XVIII. Pamplona: Eunsa, 2007, pp. 61-88.

59. ANDuEZA, Pilar. "De padre cerero a hijo marqués: José de Aldaz y Aguirre, marqués de Monte Real». En GonZÁlez Enciso, Agustín (ed.). Navarros en la Monarquía española, pp. 89-122.

60. AQuerreta, Santiago. «La casa de Arizcun, 1725-1742: las estrategias financieras de un hombre de negocios en el Madrid de la ilustración". En Ferrer Benimelli, José Antonio (dir.) y SARASA, Esteban y SERrano, Eliseo (coords.). El Conde de Aranda y su tiempo, vol. I. Zaragoza: Institución Fernando el Católico, 2000, pp. 659-678; TORRES SÁNCHEZ, Rafael. "Los navarros en la provisión de víveres de la armada española durante el siglo XVIII". En Volver a la "bora navarra". La contribución navarra a la construcción de la monarquía española en el siglo XVIII. Pamplona: Eunsa, 2010, pp. 213-264.

61. Aquerreta, Santiago (coord.). Francisco Mendinueta: Finanzas y mecenazgo en la España del siglo XVIII. Pamplona: Eunsa, 2002; GONZÁLEZ ENCISO, Agustín. "Empresarios navarros en la industria del armamento del Estado. La fábrica de Eugui». En TorRes Sánchez, Rafael (ed.). Volver a la "bora navarra", 2010, pp. 59-212.

62. SANZ AYÁN, Carmen. "Négoce, culture et sens de l'opportunité dans la construction d'un lignage. Le premier marquis de Santiago pendant la Guerre de Succession». En DubET, Anne y LuIS, Jean-Philippe (dirs.). Les financiers et la construction de l'État. France, Espagne (XVIIe-XVIIIe siècle). Rennes: Presses Universitaires de Rennes, 2011, pp. 105-124.

63. MAISO GONZÁLEZ, Jesús. La difícil modernización de Cantabria en el siglo XVIII: D. Juan Fernández de Isla y Alvear. Santander: Ayuntamiento de Santander y Librería Estudio, 1990.

64. TORRES SÁNCHEZ, Rafael. "Comercio y asientos militares. Hacia la integración comercial del Cantábrico en el siglo XVIII". Cuadernos de Investigación Histórica, 1999, 17, pp. 81-108; "Campomanes y el comerciante y financiero Simón Aragorri». En Mateos Dorado, Dolores (ed.). Campomanes doscientos años después. Oviedo: Universidad de Oviedo, 2003, pp. 709-718.

65. CARmona Badía, Xoan. "Antonio Raimundo Ibáñez, un empresario en el filo de dos épocas". En OCAMPo SuÁrez-VAldés, Joaquín (ed.). Empresas y empresarios en el norte de España (siglo XVIII). Oviedo: Trea, 2012, pp. 69-90. 
durante décadas. Con independencia de cuáles hubieran sido sus orígenes, a partir de un determinado momento se dedican a mantener sus negocios con el rey, negocios no exentos de riesgo, pero muy beneficiosos. Muchos alcanzaron la nobleza, a otros esa calidad les llegó a sus familiares, hijos o sobrinos, lo último muy frecuente en el siglo XVIII; en cualquier caso, los primeros de la saga siempre se dedicaron a los negocios e impulsaron la vida económica y financiera. Todos ellos trabajaron en compañías donde eran mayoritarios y dominantes; los socios eran parientes o gentes cercanas, pero menos adineradas e importantes. El hombre de negocios es siempre el gran personaje que domina los negocios de su casa. El nombre de casa indica el origen y naturaleza familiar de la compañía.

Muchos hombres de negocios acabaron en el ámbito de las grandes corporaciones de la segunda mitad del siglo. Una característica del capitalismo comercial del siglo XVIII es la progresiva tendencia a crear corporaciones, compañías por acciones dedicadas particularmente al comercio colonial y a las finanzas. Se adelantó, en 1728, la Compañía de Caracas $^{66}$. Las otras grandes compañías vendrían algo más tarde: la de La Habana en $1740^{67}$; luego las que fueron formando los Cinco Gremios Mayores de Madrid, hasta la Compañía de Comercio de 1752 y, sobre todo, la Compañía General y de Comercio de los Cinco Gremios Mayores de Madrid, de $1763^{68}$; la Compañía de Barcelona, o la de Filipinas, de $1785^{69}$. Todas estas compañías no solamente hicieron los negocios de ellas esperados, el comercio trasatlántico, sino que colaboraron con el Estado en multitud de tareas: asientos de abastecimiento de víveres y de armas, transporte de hombres y de armas, labores defensivas, etc., por lo que se les tiene que contar, de manera muy especial, entre los asentistas del Estado contratante.

Singular importancia en el proceso de aparición de las corporaciones tiene la creación, en 1782, del Banco de San Carlos, una compañía privada, formada por Cabarrús y sus socios, pensada para gestionar la deuda del pública -los vales reales- y hacer otro tipo de servicios financieros al Estado ${ }^{70}$. El Banco entró también en el mundo de los asientos de provisiones para las tropas.

Desde el punto de vista que nos ocupa, los asientos militares, estas corporaciones fueron sustituyendo a los principales asentistas, los hombres de negocios y

66. Gárate Ojanguren, M. ${ }^{a}$ Montserrat. La Real Compañia Guipuzcoana de Caracas. San Sebastián: Caja de Ahorros Municipal de San Sebastián, 1990.

67. GÁrate Ojanguren, M. ${ }^{a}$ Montserrat. Comercio ultramarino e ilustración. La Real Compañia de La Habana. San Sebastián: Departamento de Cultura del Gobierno Vasco, 1993.

68. Capella, Miguel y Matilla Tascón, Antonio. Los Cinco Gremios Mayores de Madrid. Estudio crítico-bistórico. Madrid: Imprenta Sáez, 1957, p. 119.

69. Oliva Melgar, José María. Cataluña y el comercio privilegiado con América en el siglo XVIII: la Real Compañia de Comercio de Barcelona a Indias. Barcelona: Publications de la Universitat de Barcelona, 1987; DíAz Trechuelo, Lourdes. La Real Compañía de Filipinas. Sevilla: Escuela de Estudios Hispano-Americanos, 1965.

70. Tedde De LorCA, Pedro. El Banco de San Carlos (1782-1829). Madrid: Alianza, 1988. 
sus casas, en el último tercio del siglo. Ciertamente, la pérdida de la posibilidad de los arrendamientos introducía un factor de debilidad en los posibles asentistas ${ }^{71}$; dado que el Estado no podía permitirse el lujo de un asentista débil, que no asegurara el abastecimiento, empezó a realizar acuerdos con algunas corporaciones. De modo particular, las compañías fueron preferidas por Esquilache frente a los anteriores asentistas, pero tanto la Compañía de Caracas como la de La Habana suscribieron acuerdos ya antes de 1760. También los Cinco Gremios de Madrid estaban operando con el Estado desde antes de esa fecha ${ }^{72}$. Más tarde será la época dorada de esta compañía y del Banco de San Carlos, que mantuvieron una estrecha competencia ${ }^{73}$.

Con Esquilache y Floridablanca, la política fue cambiando para beneficiar, en primer lugar, a los Cinco Gremios o la compañía que en cada momento encarnara sus intereses. El Banco de San Carlos apareció luego como un poderoso rival. Sus relaciones privilegiadas con el Estado, dados sus ámbitos de acción financiera, hicieron que los gobernantes le prefirieran a los Cinco Gremios; el Banco prevaleció mientras pudo aguantar el peso de la deuda.

Otro grupo de asentistas incluye a comerciantes, sin más calificativos. Hemos mencionado algunos nombres porque luego ascendieron a negocios superiores. Los que nos ocupan ahora tienen un carácter diferente. Son también comerciantes, pero siguieron siéndolo después de haber disfrutado algunos asientos; quizás no quisieron entrar en negocios mayores o no tenían medios, o relaciones, para ello. En cualquier caso, desde su posición mercantil realizaron muchas operaciones de abastecimiento, tanto contratas puntuales como asientos más duraderos. Todos formaron compañías más o menos especializadas. Fueron frecuentes en los primeros años del siglo cuando la guerra de Sucesión obligó a improvisar unos servicios que habían decaído en el final del reinado anterior ${ }^{74}$; luego, reaparecieron con fuerza en la segunda mitad, cuando el fin de los arrendamientos modificó las condiciones en las que podían trabajar los asentistas; también el crecimiento

71. GonZÁlez Enciso, Agustín. "La supresión de los arrendamientos de impuestos en la España del siglo XVIII". Tiempos Modernos, 2015, 1, p. 30, revista electrónica.

72. PÉREZ SARRIón, Guillermo. "Gremios, gremios mayores, Cinco Gremios Mayores: Madrid, 1680-1790. Una interpretación y algunas preguntas». En ANGULO MORALES, Alberto y ARAGÓN RuANO, Álvaro (eds.). Recuperando el norte. Empresas, capitales y proyectos atlánticos en la economía imperial hispánica. Bilbao: Universidad del País Vasco, 2016, pp. 19-62.

73. Torres SÁnchEZ, Rafael. "In the Shadow of Power: Monopolist Entrepreneurs, the State and Spanish Military Victualling in the Eighteenth Century». En FYNN-PAUL, J. (ed.). War, entrepreneurs, and the State in Europe and the Mediterranean.

74. TorRes SÁNCHEZ, Rafael. "Servir al rey más una comisión”. Los financieros de la Corona española durante la segunda mitad del siglo XVIII». En FERnÁndeZ AlBALADEJo, Pablo (coord.). Monarquía, Imperio y pueblos en la España Moderna. Alicante: Universidad de Alicante, 1997, pp. 149-167; DEDIEU, Jean-Pierre. "Les groupes financiers et industriels au service du roi. Espagne fin XVIIe-début XVIII $^{\mathrm{e}}$ siècle». En DuBET, Anne y LuIs, J.-P. (dirs.). Les financiers et la construction de l'État, pp. 87-104. 
de la marina y del ejército ofreció nuevas oportunidades, más allá de los grandes asientos controlados por las compañías privilegiadas.

Su experiencia mercantil les permitió concentrarse en algún producto y controlar los asientos de ese sector. Es el caso de los comerciantes de jarcias y lonas ${ }^{75}$, o de los vestuarios del ejército ${ }^{76}$. En otros casos no dominaron ningún campo en particular, sino que tuvieron asientos de manera más o menos puntual, como fueron los hermanos Soto, Guendica, Pedrueza, Manuel Santibáñez, Retortillo y otros $^{77}$. Muchas de estas contratas, más o menos parciales, o asientos por períodos cortos de tiempo tenían lugar en los arsenales, un mundo donde confluía la organización estatal del arsenal con los abastos necesarios para la construcción y atención de los barcos, suministrados por particulares ${ }^{78}$. Salvo en el caso de las jarcias y de los uniformes, la información que tenemos de estos comerciantes y de otros posibles es escasa ${ }^{79}$, pero suficiente para hacernos cargo de que sus negocios fueron más o menos puntuales. El elenco podría ser largo, lo que atestigua las numerosas necesidades de la Corona y la variedad de personas a las que se acudió, para remediarlas, a lo largo del siglo.

\subsection{Gremios de artesanos y otras instituciones sociales: la sociedad en general}

Los grupos mencionados hasta aquí solían encargarse de grandes asientos de productos comprados en grandes cantidades o caros. Pero los productos demandados eran muy variados y podían condicionar el oferente. Algunos objetos solamente se producían, según larga tradición, en el entorno de gremios artesanales y no era fácil arrebatarles el negocio, ellos tenían la técnica de la mejor producción y calidad. Hay un caso paradigmático, el de las armas de fuego de mano, pistolas

75. DíAz-OrdóÑEz, Manuel. Amarrados al negocio. Reformismo borbónico y suministro de jarcia para la Armada Real (1675-1751). Madrid: Ministerio de Defensa, 2009; "El abastecimiento militar de cáñamo para el imperio español (1665-1808): globalización, Estado y empresarios en el largo Siglo XVIII». Espacio, Tiempo y Forma. Serie IV. Historia Moderna, 2019, 32, pp. 45-72.

76. SOlBES FERRI, Sergio. "Contracting and Accounting: Spanish Army Expenditure in Wardrobe and the General Treasury Accounts in Eighteenth Century». En HARDING, Richard y SolBes Ferri, Sergio (eds.). The Contractor State and its Implications, 1659-1815. Las Palmas de Gran Canaria: Universidad de Las Palmas, 2012, pp. 273-294; "Campillo y Ensenada: el suministro de vestuarios para el ejército durante las campañas de Italia (1741-1748)». Studia Historica. Historia Moderna, 2013, 35, pp. 201-234; "Gasto militar y agentes privados. La provisión de uniformes para el ejército español en el siglo XVIII". Tiempos Modernos, 2015, 8, p. 30, revista electrónica.

77. GonzÁlez Enciso, Agustín. "Herrajes para la Marina. La concesión del asiento de 1762». Anuario de Estudios Atlánticos, 2019, 65, pp. 1013-1046.

78. TORRES SÁNCHEZ, Rafael. "Producir o comprar. La demanda de la Corona española de productos industriales en el siglo xVIII. En Ribot García, Luis A. y De Rosa, Luigi (dirs.). Industria y Época Moderna. Madrid: Actas e Istituto Italiano per gli Studi Filosofici, 2000, pp. 95-131.

79. Muchos nombres se citan en Merino Navarro, José Patricio. La Armada española en el siglo XVIII. Madrid: Fundación Universitaria Española, 1981, cap. IV, reeditado en Madrid: Ediciones 19, 2019. 
y fusiles. Desde tiempo atrás, había gremios de armeros especializados, particularmente en algunas zonas de Cataluña ${ }^{80}$ y en Placencia de las Armas, en Guipúzcoa $^{81}$. Allí siguieron fabricándose. Otra cosa es que el asiento para la provisión al rey lo firmara un representante de los gremios - que coordinaba el contrato- o una compañía, como fue, durante algún tiempo, la Compañía de Caracas. Algo similar ocurría con las espadas, fabricadas, sobre todo, por los armeros de Toledo hasta que se creó una fábrica estatal ${ }^{82}$. Evoluciones parecidas siguieron otros productos muy diferentes, como las lonas para velas y las anclas ${ }^{83}$. Los gremios acabaron perdiendo el asiento en algunos casos, no obstante, ellos también fueron asentistas durante mucho tiempo.

Los gremios conectan con amplios sectores de la sociedad. La variedad de situaciones que la sociedad estamental ofrecía era grande. Estamos acostumbrados a que las funciones de producción y distribución las realicen entidades económicas; pero no siempre era así. En ocasiones, el Estado podía proveerse de unas tierras, o de bosques y minas, cuyos propietarios no eran comerciantes ni negociantes. Muy frecuentemente, esos bienes tenían propietarios variados: un ayuntamiento, un convento, un noble, cualquier particular. Tales propietarios solían usar la producción para su propio consumo, pero en ocasiones preferían venderla. También en estos casos el Estado y sus necesidades se presentaban como ocasiones para conseguir la venta de los excedentes.

La historiografía británica, en particular, ha sido explícita al ampliar el concepto de asentista desde los grandes a todos los que tuvieran relación comercial con alguna agencia estatal. Muchos formaban grupos de asentistas articulados por la especialización en tipos de suministros que podían atraer el trabajo de muchas personas. En la práctica, hay que reconocer la existencia de multitud de contratistas que trabajaban para varias demandas del Estado y representaban, de hecho, a numerosas capas sociales ${ }^{84}$. Algo similar ocurría en otros países: nobles, burgueses, líderes militares, incluso bucaneros y condotieros, así como todo tipo de comerciantes y de compañías comerciales se pueden sumar a la lista de individuos e instituciones que participaban en la movilización de recursos. Estamos, pues, ante un auténtico universo social de contratistas.

80. MARTí, R. Cataluña armería de los Borbones. Las armas y los armeros de Ripoll, Barcelona, Manresa, Igualada... de 1714 a 1794. Barcelona: Salvatella, 2004.

81. Calvo Poyato, Jesús. «La industria militar española durante la Guerra de Sucesión». Revista de Historia Militar, 1989, 66, pp. 51-71; GONZÁlez ENCISO, Agustín. War, Power and the Economy, pp. 34-37.

82. Peris SÁnchez, Diego; LuCAs Martínez, Antonio y AlCalde, Ángel. La fábrica de armas de Toledo. Historia. Ciudad Real: Universidad de Castilla-La Mancha, 1999.

83. TORRES SÁnCHEZ, Rafael. Military Entrepreneurs, pp. 18, 178, 190 y ss.

84. KNIGHT, Roger y WilcoX, M. Sustaining the Fleeet, 1793-1815: War, the British Navy and the Contractor State. Woodbridge: The Boydell Press, 2010; Graham, Aaron y Walsh, P. (eds.). The British Fiscal-Military States, 1660-c. 1783. Londres: Routledge, 2016. 
Todas esas personas, interesadas en participar en los negocios del rey, no buscaban solo una posible ganancia. Como los grandes, que conseguían títulos o influencia en la corte, las gentes sencillas deseaban privilegios de diferente tipo, no menos portadores de dignificación social, como el prestigio de portar armas a los artesanos que producían sables, la exención de reclutamiento para la tripulación de los buques que transportaban hierro al arsenal o el prestigio social que suponía portar una escarapela del rey. Tenemos pocos ejemplos de la colaboración del conjunto social, para el caso español. Se pueden citar algunos, como el de un colegio de jesuitas que pugnó por hacerse con el contrato de corta de madera para el ejército, en un bosque del sur de España, o la subcontratación a gremios o corporaciones municipales ${ }^{85}$.

Todo ello podía tener mayor efecto por los pagos realizados localmente a instituciones, carreteros, molineros, artesanos o agricultores. Eso quiere decir que la participación del conjunto social en los abastecimientos militares se puede ver desde la perspectiva de las grandes cadenas de producción o distribución. La provisión de grano depende del asentista general, pero implica a comerciantes locales y a los productores mismos, por no hablar de los transportistas. Las balas de cañón exigían la explotación de la madera del bosque, piedras para los altos hornos, transporte de la materia prima a la fábrica y del producto elaborado hasta un destino lejano. En definitiva, cada producto exige una variedad de servicios intermediarios enlazados; todos ellos son beneficiarios de la demanda estatal y son, de alguna manera, asentistas del Estado. Esos colectivos indican que la movilización de recursos militares relacionaba al Estado con el conjunto social ${ }^{86}$.

\subsection{El protagonismo directo del Estado: arsenales y fábricas estatales}

Otra realidad típica de la España del XVIII es la existencia de instituciones de suministro de abastecimientos propiedad del Estado, del que dependían su gestión y su financiación. Es el «Estado fabricante», por oposición al "Estado contratante» ${ }^{87}$, que no compraba, sino que fabricaba los productos que necesitaba. ¿Cabe decir que el Estado era su propio asentista? En cierto modo sí; en cualquier caso, lo que está claro es que el Estado español optó, según circunstancias, por fabricar, frente a comprar. La fabricación estatal es así, una forma más de abastecimiento del Estado.

85. TORRES SÁNCHEZ. Military Entrepreneurs, 2016.

86. Las ponencias de un reciente congreso muestran la variedad de asentistas, grandes y pequeños, permanentes y ocasionales que abastecieron a ejércitos y armadas españolas, tanto en la España metropolitana como en América, en Italia o en Austria. Congreso Internacional. Alimentando a Marte: Los empresarios militares del "contractor state» en los siglos XVII y XVIII. Segovia, Academia de Artillería, pp. 22-24 de octubre de 2019.

87. GONZÁLEZ ENCISO, Agustín. "Del "contractor state" al Estado fabricante. El cambio de propiedad en la fábrica de municiones de Eugui en 1766”. Revista de Historia de la Economía y de la Empresa, 2013, VII, pp. 455-484. 
El primer ejemplo data de 1717 , con la fábrica de paños de Guadalajara ${ }^{88}$. Los objetivos que se pretendieron eran muy variados, pero incluían el abastecimiento al ejército de paños para uniformes de oficiales y, más tarde, de telas para banderas de barcos. Con esta y otras empresas ${ }^{89}$, el Estado obtuvo experiencia de gestión directa en el sector de la producción. Pero la idea de introducir la administración directa en abastecimientos clave llegaría más tarde.

El modelo se ensayó en el abastecimiento de víveres al ejército ${ }^{90}$ y en los uniformes $^{91}$, durante los años treinta y cuarenta. El intento fue como una mezcla del modelo británico - una agencia estatal que centralizaba las compras, aunque se hacían a comerciantes particulares según mercado- ${ }^{92}$ y el deseo centralizador de los gobernantes españoles, particularmente de Patiño. El ensayo no salió bien y, tras unos años de prueba, se volvió al sistema de asientos. Más intensidad y permanencia tuvo otra oleada de centralismo que apareció en 1760, con la llegada de Carlos III. Su experiencia napolitana le había mostrado el éxito de las fábricas estatales en varios ámbitos, incluido el militar. En España las empresas estatales contaban entonces con menos adeptos, pero no era esa la postura del rey. La nueva política recuperó la gestión estatal de empresas que habían sido cedidas temporalmente a particulares, y estatalizó las empresas de armamento que hasta entonces habían sido empresas privadas privilegiadas.

Desde el inicio del reinado se realizaron acciones tendentes a la estatalización de las fábricas de cañones de hierro colado de Liérganes y La Cavada, cuyo proceso se llevó a cabo a partir de $1760^{93}$; luego se seguiría con la de municiones de Eugui ${ }^{94}$ y, poco después, con la participación completa del Estado en la gestión de las fábricas de cañones de bronce de Sevilla y Barcelona ${ }^{95}$ y con la creación de otras fábricas de municiones de hierro en diferentes localidades de España ${ }^{96}$. La estatalización del

88. GonZÁlez EnCISO, Agustín. Estado e industria: la Real Fábrica de paños de Guadalajara. Madrid: Fundación Universitaria Española, 1980.

89. Helguera Qujada, Juan. "Las Reales Fábricas». En Martín AceÑa, Pablo y Comín, Francisco (coords.). Historia de la empresa pública en España. Madrid 1991, pp. 51-88.

90. TorRes SÁNCHEZ, Rafael. "Cuando las reglas del juego cambian. Mercados y privilegio en el abastecimiento del ejército español en el siglo XVIII. Revista de Historia Moderna. Anales de la Universidad de Alicante, 2002, 20, pp. 487-511.

91. SOlBES FERrI, Sergio. "Campillo y Ensenada. El suministro de vestuario para el ejército".

92. Bannerman, G. E. Merchants and the Military in Eighteenth-century Britain. Londres: Pickering and Chato, 2008.

93. AlCALÁ-Zamora, José. Liérganes y La Cavada. Historia de los primeros altos hornos españoles (1622-1834). Santander: Estudio, 2004.

94. GonZÁlez ENCISO, Agustín. Un Estado militar: España, 1650-1820. Madrid: Actas, 2012, pp. 423-447; "Del "contractor state" al Estado fabricante".

95. Aguilar Escobar, Antonio. Cañones de bronce para el Ejército. Historia de la Real Fundición de Sevilla en el siglo XVIII. Madrid: Ministerio de Defensa, 2010.

96. RABANAL Yus, Aurora. Las reales fundiciones españolas del siglo XVIII. Madrid: Estado Mayor del Ejército, 1990; AlCALÁ-ZAMORA, José. Altos hornos y poder naval en la España de la Edad Moderna. Madrid: Academia de la Historia, 1999; ADARO RUIZ-FALCó, L. Los comienzos de las fábricas 
sector tuvo luces y sombras. Se pretendió mejorar la calidad, implementar nuevas tecnologías, ganar en control y rebajar costes. Poco de esto se consiguió. Los éxitos fueron escasos y caros. La renovación del sector, que estaba ligada a la mejora de toda la metalurgia del hierro en general ${ }^{97}$, no se consiguió. Hubo otras empresas estatales de armamento como la fábrica de espadas de Toledo, que sustituyó al abastecimiento gremial tradicional; una fábrica de fusiles en Silillos, que no prosperó, o las fábricas de anclas de Renteriola, Guipúzcoa, en $1749^{98}$, y de Marrón, Cantabria, a comienzos del siglo XIX.

El otro ámbito estatal característico es el de los arsenales. Creados a partir de 1726 por Patiño, tardaron tiempo en resultar operativos. Se trataba de centros fabriles dedicados al resguardo y mantenimiento de las escuadras de la Marina real, donde se realizaban todo tipo de operaciones y se fabricaban los materiales necesarios. Cada arsenal contó con un astillero, más o menos activo, y, en la segunda mitad del siglo, con diques secos y otros avances técnicos. Se establecieron en Ferrol, Cádiz, Cartagena y La Habana99.

Sobre los arsenales nos interesa señalar dos cosas. La primera, que eran empresas estatales, pero una gran cantidad de actividades las realizaban empresarios particulares que subcontrataban sus servicios y podían realizar sus tareas dentro de los muros del arsenal. El arsenal se convertía, así, en centro de gestión, almacenamiento y distribución de los productos necesarios para las escuadras y su mantenimiento. El segundo aspecto a señalar es que la construcción de los barcos se hizo, salvo algún período breve, por contratación con particulares. Al igual que en San Feliú de Guixols, en Pasajes o luego en Guarnizo -astilleros para la construcción de los navíos-, a comienzos de siglo, los nuevos arsenales -particularmente Ferrol y La Habana, que fueron los que construyeron la mayoría de los barcos- prestaban sus instalaciones a los particulares que negociaban la construcción de los barcos. Los asentistas contrataban el material y coordinaban todas las

de municiones gruesas de Trubia y de armas de Oviedo: 1792-1799. Oviedo: Imprenta La Cruz, 1986; Tielve García, Natalia (coord.). La Real Fábrica de armas de Trubia: Patrimonio de la industrialización en España. Gijón: CICEES. Centro de Iniciativas Culturales, 2010.

97. Helguera QuiJADA, Juan. «De La Cavada a Trubia. Intervencionismo estatal y cambio tecnológico en las fundiciones de artillería del norte de España (1760-1800)». En OCAMPO SuÁrEZ-VALDÉs, Joaquín (ed.). Empresas y empresarios en el norte de España (Siglo XVIII). Oviedo: Trea, 2012, pp. 153-182.

98. OdRIOZOla OyARBide, M. ${ }^{a}$ Lourdes. "La industria naval guipuzcoana y la producción de navíos para el rey (1650-1799)». Boletín de la Real Sociedad Bascongada de los Amigos del País, 1994, 1, pp. 3-41.

99. Merino Navarro, José Patricio. "Graving Docks in France and Spain Before 1800». Mariner's Mirror, 1985, 71, 1, pp. 35-58; "La città e l'arsenale di El Ferrol nel XviII secolo». En ConcinA, E. (a cura di). Arsenali e città nell'Occidente europeo. Roma: NIS, 1987, pp. 175-188; TORREJón CHAVES, Juan. "Estructura y organización de la producción en los arsenales de la Marina española del siglo XVIII". Revista de Historia Naval, 2001, 74, pp. 55-82; SERRANo Álvarez, José Manuel. El astillero de La Habana en el siglo XVIII. Madrid: Ministerio de Defensa, 2018. 
labores, si bien la construcción estaba sometida a la dirección del ingeniero naval correspondiente, funcionario del Estado ${ }^{100}$.

\section{Conclusiones}

Hemos repasado la historiografía sobre dos cuestiones relativas a los medios necesarios para hacer la guerra. ¿Qué resalta en ambos casos? Respecto a los dineros podríamos preguntarnos si la fiscalidad de guerra fue suficiente para pagar todas las necesidades. La realidad es que, al menos hasta 1794, las guerras se pagaron y el resultado estratégico, a la altura de 1790, era positivo. ¿Por qué fue luego tan rápido y desastroso el final? Posiblemente porque las guerras no se pagaron por el mejor método. España aumentó sus ingresos gracias a medidas administrativas - la administración directa- o por la vía de los monopolios -metales y tabaco-, pero no consiguió aumentar la base fiscal. Las medidas fundamentales -reforma de las alcabalas, comercio libre con América- fueron tardías, y la deuda pública, también tardía, se encontró con poca base: no había ambiente ni se había ido preparando el mercado de modo progresivo. Si los recursos existían, no fue fácil hacerlos aflorar. Al final, hubo que volver al endeudamiento de manera algo desordenada. En definitiva, los modos que se eligieron para pagar las guerras consiguieron financiarlas, pero no aumentaron la base fiscal ni fueron eficaces para generar suficientes beneficios indirectos.

Las razones pueden estar en que en el siglo XVIII se vivió un sentimiento de dependencia negativa respecto a lo ocurrido en el siglo XVII. España huyó de lo que se había hecho: se procuró no subir mucho los impuestos y no endeudarse. Esto produjo una doble consecuencia. Si, por una parte, los españoles no se empobrecieron por la fiscalidad, por otra, al Estado le fue difícil ingresar las cantidades necesarias para hacer la guerra o aumentar la base fiscal. Eso limitó las posibilidades de acción militar. Afectó también a los asentistas que se vieron forzados a realizar contratos a precios bajos, mientras el Estado pagaba tarde y mal porque no había suficiente dinero.

Respecto a los asentistas, el trabajo muestra que identificarlos con los grandes hombres de negocios es correcto, pero limitado. La realidad es que tanto las enormes necesidades de las Fuerzas Armadas como las diferentes coyunturas por las que un ejército o una expedición marítima podían pasar obligaban a abastecerse de las formas más variadas posibles. No había solo asientos generales, también había asientos de menor importancia que cubrían una oferta variada y contratas puntuales. Todo esto lleva a pensar en la colaboración entre el Estado y la sociedad, de manera general, y en una amplia tipología de asentistas.

100. Merino Navarro, José Patricio. La Armada española en el siglo XVIII; VAldez-Bubnov, Iván. Poder naval y modernización del Estado. 
El suministro de cada producto dependía de la forma tradicional de producir esa mercancía. Los víveres dependían de los agricultores y de las compañías distribuidoras de cereales, carne, vino, etc., como ocurría con el resto de la población. Los uniformes se hacían en talleres textiles tradicionales y las armas siguieron su tradición fabril: las de mano, una tradición gremial; los cañones una diferente, por su fabricación compleja. Todas esas formas de producción, o de localización del producto, con sus exigencias económicas y organizativas, favorecieron la entrada de un tipo de asentista u otro.

La evolución política tuvo diferentes tendencias. A comienzos de siglo dominaba la presencia de comerciantes franceses; poco a poco se produjo una españolización de la provisión. La supresión de los arrendamientos de impuestos hizo evolucionar el tipo de asentistas, como lo hicieron, igualmente, las preferencias de los ministros del ramo. También cabe señalar una diferencia entre los asientos de guerra y los de tiempos de paz. La guerra obliga a un abastecimiento exhaustivo: urgente, variante, preciso. Hay que improvisar y conseguir lo necesario por cualquier cauce; no así en tiempo de paz. Un problema de la paz era la ausencia de pedidos; desaparecían las peticiones extraordinarias, pero también se demandaba menos de lo estipulado en los asientos. Por lo tanto, si los plazos del asiento se alargaban en años de paz, el asentista podía tener problemas.

En definitiva, el Estado ejercía una demanda importante, pero oscilante y sujeta a variadas circunstancias, lo que complicaba la gestión empresarial. Si el asiento era una actividad más entre otras habituales del empresario, suponía un ingreso extra beneficioso; pero si el asentista se concentraba en exceso en su gran cliente, podía encontrarse con que la demanda bajaba de golpe y no tenía alternativa para su negocio.

¿Fue la guerra un motor de la actividad empresarial? La guerra ciertamente generó una actividad empresarial importante y variada, aunque sus resultados cuantitativos son difíciles de apreciar. En todo caso, los asentistas se enfrentaban a muchos problemas. Trabajando con precios muy ajustados -el rey regateaba el precio hasta extremos intolerables-, obligados a cumplir de manera escrupulosa -lo que hacían normalmente-, sometidos a una demanda variable, no parece que los asentistas y sus empresas pudieran ser la base de ninguna gran actividad empresarial firme. El impacto positivo de sus beneficios fue temporal y se evaporó con facilidad. No es extraño que los asentistas acabaran accediendo al asiento porque les interesaban otros beneficios no económicos: influencia social o local, acceso a la corte y a sus privilegios, posibilidad de ennoblecimiento, etc., e hicieran inversiones suntuarias; en todo caso, también habría que tener en cuenta el impacto positivo de estas inversiones.

Queda valorar si la explotación de los productos a abastecer, que Uztáriz decía que abundaban en España, favoreció un aumento de su producción o fabricación. Es claro que creció la demanda de tales productos. El problema, sin embargo, reside en la cantidad y en la continuidad. España no quiso embarcarse en una actitud de guerra permanente a gran escala, sino que, salvo excepciones, 
se limitó a responder a las agresiones externas para luego volver a la paz, aunque a veces fuera "paz armada». Por todo ello, cabe decir que la guerra, en la España del siglo XVIII, fue motor de la actividad económica y empresarial, pero un motor relativamente limitado.

\section{BiBLIOGRAFÍA}

ADARO RUIZ-FALCÓ, L. Los comienzos de las fábricas de municiones gruesas de Trubia y de armas de Oviedo: 1792-1799. Oviedo: Imprenta La Cruz, 1986.

Aguilar Escobar, Antonio. Cañones de bronce para el Ejército. Historia de la Real Fundición de Sevilla en el siglo XVIII. Madrid: Ministerio de Defensa, 2010.

AlCAlÁ-ZAmora, José. Altos hornos y poder naval en la España de la Edad Moderna. Madrid: Academia de la Historia, 1999.

AlCAlá-Zamora, José. Liérganes y La Cavada. Historia de los primeros altos hornos españoles (1622-1834). Santander: Estudio, 2004.

ANDuEZA, Pilar. "De padre cerero a hijo marqués: José de Aldaz y Aguirre, marqués de Monte Real». En GonZÁlez EnCISO, Agustín (ed.). Navarros en la Monarquía española, pp. 89-122.

ANDÚJAR CASTILLO, Francisco. «Juan de Goyeneche. Financiero, tesorero de la reina y mediador en la venta de cargos». En González EnCISO, Agustín (ed.). Navarros en la Monarquía española en el siglo XVIII. Pamplona: Eunsa, 2007, pp. 61-88.

Angulo Teja, Carmen. La Hacienda española en el siglo XVIII. Las rentas provinciales. Madrid: Centro de Estudios Políticos y Constitucionales, 2002.

AQuerReTA, Santiago. "La casa de Arizcun, 1725-1742: las estrategias financieras de un hombre de negocios en el Madrid de la ilustración». En Ferrer Benimelli, José Antonio (dir.) y SARASA, Esteban y SERrano, Eliseo (coord.). El Conde de Aranda y su tiempo. vol. I. Zaragoza: Institución Fernando el Católico, 2000, pp. 659-678.

AQuerreTA, Santiago. Negocios y finanzas en el siglo XVIII: la familia Goyeneche. Pamplona: Eunsa, 2000.

AQuerreta, Santiago (coord.). Francisco Mendinueta: Finanzas y mecenazgo en la España del siglo XVIII. Pamplona: Eunsa, 2002.

Artola, Miguel. La Hacienda del Antiguo Régimen. Madrid: Alianza, 1982.

Bannerman, G. E. Merchants and the Military in Eighteenth-century Britain. Londres: Pickering and Chato, 2008.

BARBIER, J. A. "Towards a New Chronology for Bourbon Colonialism: The "Depositaría de Indias" of Cadiz, 1722-1789". Ibero-AmeriKanisches Archiv, 1980, 6, 4, pp. 341-342.

BARBIER, J. A. y KLEIN, H. S. «Las prioridades de un monarca ilustrado: el gasto público bajo el reinado de Carlos III. Revista de Historia Económica, 1985, 3, pp. 473-495.

BLACK, J. A. A Military Revolution? Military Change and European Society, 1550-1800. Londres: Macmillan, 1991.

Bowen, H. V. War and British Society, 1688-1815. Cambridge: Cambridge U. P., 1998.

Bowen, Huw y GonZÁlez EnCISO, Agustín (eds.). Mobilising Resources for War: Britain and Spain at Work during the Early Modern Period. Pamplona: Eunsa, 2006.

Bowen, H. V. et al. "Forum: The Contractor State, c. 1650-1815". International Journal of Maritime History, 2013, XXV, 1, pp. 239-274. 
Brewer, John. The Sinews of Power. War, Money and the English State, 1688-1783. Londres: Unwin Hyman.

Calvo Poyato, Jesús. «La industria militar española durante la Guerra de Sucesión». Revista de Historia Militar, 1989, 66, pp. 51-71.

Capella, Miguel y Matilla Tascón, Antonio. Los Cinco Gremios Mayores de Madrid. Estudio crítico-bistórico. Madrid: Imprenta Sáez, 1957.

Carmona Badía, Xoan. "Antonio Raimundo Ibáñez, un empresario en el filo de dos épocas». En OCAMPO SuÁrEZ-VALDÉs, Joaquín (ed.). Empresas y empresarios en el norte de España (siglo XVIII). Oviedo: Trea, 2012, pp. 69-90.

CAstellano, Juan Luis. Gobierno y poder en la España del siglo XVIII. Granada: Universidad de Granada, 2006.

Congreso Internacional. Alimentando a Marte: Los empresarios militares del "contractor state" en los siglos XVII y XVIII. Segovia, Academia de Artillería, 22-24 de octubre de 2019.

Cuenca Esteban, Javier. «Statistics of Spain's Colonial Trade, 1792-1820». Hispanic American Historical Review, 1981, 61, pp. 381-428.

Deans-Smith, Susan. «The Money Plant: The Royal Tobacco Monopoly of New Spain, 1765-1821». En JACOBSEn, Nils y Puhle, Hans-Jürgen (eds.). The Economies of New Mexico and Peru During the Late Colonial Period, 1760-1810. Berlín: Colloquium Verlag, 1986, pp. 361-387.

Dedieu, Jean-Pierre. "Les groupes financiers et industriels au service du roi. Espagne fin XVIIe-début XVIII siècle». En DuBET, Anne y LuIS, J.-P. (dirs.). Les financiers et la construction de l'État, pp. 87-104.

Díaz Trechuelo, Lourdes. La Real Compañia de Filipinas. Sevilla: Escuela de Estudios Hispano-Americanos, 1965.

DÍAZ-ORDÓÑEZ, Manuel. Amarrados al negocio. Reformismo borbónico y suministro de jarcia para la Armada Real (1675-1751). Madrid: Ministerio de Defensa, 2009.

DíAZ-ORDÓÑEZ, Manuel. «El abastecimiento militar de cáñamo para el imperio español (1665-1808): globalización, Estado y empresarios en el largo Siglo XVIII. Espacio, Tiempo y Forma. Serie IV. Historia Moderna, 2019, 32, pp. 45-72.

DuBET, Anne. "La suspensión de pagos de 1739: ¿una medida de "buen gobierno" de la Hacienda?». Espacio, Tiempo y Forma, 2017, 30, pp. 19-56.

Dubet, Anne y SOlBes FerRI, Sergio. El rey, el ministro y el tesorero. El gobierno de la Real Hacienda en el siglo XVIII español. Madrid: Marcial Pons, 2019.

ENCISO RECIO, Luis Miguel. «El fin del gran tráfico atlántico español». En José ALCALÁ-ZAMORA (coord.). La España oceánica de los siglos modernos y el tesoro submarino español. Madrid: Real Academia de la Historia y Marquesa Viuda de Arriluce de Ybarra, 2008, pp. 253-312.

FÉ CANTÓ, Luis Fernando. «El desembarco en Orán en 1732. Aproximación analítica a una operación compleja». Revista Universitaria de Historia Militar, 2016, 5, 10, pp. 89-110.

Fernández Albaladejo, Pablo. "El decreto de suspensión de pagos de 1739: análisis e implicaciones». Moneda y Crédito, 1977, 142, pp. 51-81.

FERnÁNDEZ DE Pinedo EChevarría, Nadia. «Jenkins Ear and Tax Collection in Spain in the 18th Century». Presentado en XV International Economic History Congress, Utrecht, 2009.

FISHER, John. Commercial Relations between Spain and Spanish America in the Era of Free Trade, 1778-1796. Liverpool, 1985.

Gárate Ojanguren, M. ${ }^{a}$ Montserrat. La Real Compañía Guipuzcoana de Caracas. San Sebastián: Caja de Ahorros Municipal de San Sebastián, 1990. 
Gárate Ojanguren, M. ${ }^{a}$ Montserrat. Comercio ultramarino e ilustración. La Real Compañía de La Habana. San Sebastián: Departamento de Cultura del Gobierno Vasco, 1993.

García-BAquero GonzÁlez, Antonio. Comercio colonial y guerras revolucionarias. Sevilla: Escuela de Estudios Hispano-Americanos, 1972.

García-Baquero González, Antonio. "El comercio colonial en el cambio de siglo: De la apertura a la quiebra del sistema monopolístico español». En MOrales Moya, Antonio (coord.). 1802. España entre dos siglos y la recuperación de Menorca. Madrid: Sociedad Estatal de Conmemoraciones Culturales, 2003.

García-BAQuero González, Antonio. El comercio colonial en la época del absolutismo ilustrado. Problemas y debates. Granada: Universidad de Granada, 2003.

GLETE, John. War and the State in Early Modern Europe: Spain, the Dutch Republic and Sweden as Fiscal-Military States, 1500-1650. Londres, 2002.

Gómez URDÁÑEz, José Luis. El proyecto reformista de Ensenada. Lérida: Milenio, 1996.

GonzÁlez Enciso, Agustín. Estado e industria: la Real Fábrica de paños de Guadalajara. Madrid: Fundación Universitaria Española, 1980.

González Enciso, Agustín. «Tabaco y Hacienda, 1670-1840». En Alonso, Luis; Gálvez MuÑOZ, Lina y DE LuXÁN, Santiago (eds.). Tabaco e historia económica. Madrid: Fundación Altadis, 2006, pp. 43-69.

GonZÁlez ENCISO, Agustín. «Spain's Mobilisation of Resources for the War with Portugal in 1762». En Bowen, Huw y González Enciso, Agustín (eds.). Mobilising Resources for War, 2006, pp. 159-190.

GonZÁlez Enciso, Agustín. "A Moderate and Rational Absolutism. Spanish Fiscal Policy in the First Half of the Eighteenth Century». En Torres SÁnchez, Rafael (ed.). War, State and Development: Fiscal-military States in the Eighteenth Century. Pamplona: Eunsa, 2007, pp. 109-132.

GONZÁLEZ ENCISO, Agustín. «Empresarios navarros en la industria del armamento del Estado. La fábrica de Eugui». En TORReS SÁnchez, Rafael (ed.). Volver a la "bora navarra", 2010, pp. 59-212.

GonZález Enciso, Agustín. «La Guerra de la Oreja de Jenkins. Política y economía». En Díaz Benítez, Juan José; Galván Rodríguez, Eduardo y De Luxán Meléndez, Santiago (eds.). Conflictos bélicos y relaciones internacionales (1739-1927). Tenerife: Ediciones Idea, 2011, pp. 27-87.

GonzÁlez Enciso, Agustín (ed.). Un Estado militar: España, 1650-1820. Madrid: Actas, 2012.

GONZÁlez ENCISO, Agustín. «Del contractor state al Estado fabricante. El cambio de propiedad en la fábrica de municiones de Eugui». Revista de Historia de la Economía y de la Empresa, 2013, VII, pp. 455-484.

GONZÁLEZ ENCISO, Agustín. «La supresión de los arrendamientos de impuestos en la España del siglo XVIII. Tiempos Modernos, 2015, 1, p. 30, revista electrónica.

GonZÁlez EnCISO, Agustín. War, Power and the Economy. Mercantilism and State Formation in 18th-Century Europe. Londres: Routledge, 2017.

GonZÁlez Enciso, Agustín. "Between Private and Public Interests: the Moral Economy of Collaboration in Eighteenth-century Spain». En FÉlIx, Joël y Dubet, Anne (eds.). The War Within. Private Interests and the Fiscal State in Early-Modern Europe. Cham (Suiza): Palgrave-Macmillan, 2018, pp. 171-194.

GONZÁlEZ ENCISO, Agustín. "War contracting and artillery production in Spain». Business History, 2018, 60, 1, pp. 87-104. 
GonZÁlez Enciso, Agustín. "Pagar la batalla. Campillo y el dinero para el ejército de Nápoles y Lombardía, 1734-1736", en prensa. Se presentó en Congreso Internacional: Renovar y difundir la Historia Militar. La batalla como protagonista de la historia. Segovia, pp. 27-28 de septiembre de 2018.

GONZÁlez Enciso, Agustín. "Herrajes para la Marina. La concesión del asiento de 1762». Anuario de Estudios Atlánticos, 2019, pp. 65, 1013-1046.

Graham, Aaron y Walsh, P. (eds.). The British Fiscal-Military States, 1660-c. 1783. Londres: Routledge, 2016.

Hamilton, Earl J. Guerra y precios en España, 1651-1800. Madrid: Alianza, 1988.

Helguera Quijada, Juan. «Las Reales Fábricas». En MarTín Aceña, Pablo y Comín, F. (coord.). Historia de la empresa pública en España. Madrid, 1991, pp. 51-88.

Helguera QUiJADA, Juan. «De La Cavada a Trubia. Intervencionismo estatal y cambio tecnológico en las fundiciones de artillería del norte de España (1760-1800)». En OcAMPO SuÁREZ-VALdÉs, Joaquín (ed.). Empresas y empresarios en el norte de España (Siglo XVIII). Oviedo: Trea, 2012, pp. 153-182.

JuRADO SÁnCHEZ, José. El gasto de la Hacienda española durante el siglo XVIII. Cuantía y estructura de los pagos del Estado (1703-1800). Madrid: Instituto de Estudios Fiscales, 2006.

KAMEN, Henry. La Guerra de Sucesión en España, 1700-1715. Barcelona: Grijalbo, 1974.

KLeIN, Herbert. Las finanzas americanas del imperio español, 1680-1809. México: Instituto Mora y U. Autónoma de México, 1994.

KNIGHT, Roger y Wilcox, M. Sustaining the Fleeet, 1793-1815: War, the British Navy and the Contractor State. Woodbridge: The Boydell Press, 2010.

LuXÁn, Santiago de (dir.). Política y hacienda del tabaco en los imperios ibéricos (siglos XVII-XIX). Madrid: Centro de Estudios Políticos y Constitucionales, 2014.

MaIso González, Jesús. La difícil modernización de Cantabria en el siglo XVIII: D. Juan Fernández de Isla y Alvear. Santander: Ayuntamiento de Santander y Librería Estudio, 1990.

MARICHAL, Carlos. La bancarrota del virreinato. Nueva España y las finanzas del imperio español, 1780-1850. México: Fondo de Cultura Económica, 1999.

Marichal, Carlos y vON Grafenstein, Johana (coords.). El secreto del imperio español: los situados coloniales en el siglo XVIII. México: Instituto Mora, 2012.

MARINA BARBA, J. «La contribución extraordinaria del diez por ciento de las rentas de 1741». Chronica Nova, 1993-1994, 21, pp. 279-355.

MARTí, Eduard. "Cataluña y la movilización de recursos militares para la expedición a Sicilia de 1718". En Congreso Internacional Renovar y Difundir la Historia Militar. Madrid; Casa de Velázquez y UNED, 27-29 de septiembre de 2017.

MARTí, R. Cataluña armería de los Borbones. Las armas y los armeros de Ripoll, Barcelona, Manresa, Igualada... de 1714 a 1794. Barcelona: Salvatella, 2004.

MARTín CORRALES, Eloy. "Cataluña era una fiesta. Las celebraciones por la toma de Orán». En Bunes IbarRa, Miguel Ángel y Alonso Acero, Beatriz (coords.). Orán: historia de la corte chica. Madrid: Polifemo, 2011, pp. 119-142.

Martínez Ruiz, Enrique. Los soldados del rey. Los ejércitos de la monarquía hispánica (1480-1700). Madrid: Actas, 2008.

Martínez Ruiz, Enrique. Historia militar de la Europa Moderna. Madrid: Síntesis, 2016.

Melón JiméneZ, Miguel Ángel. "Las rentas provinciales y la idea de una sola contribución real de Miguel Zavala y Auñón». En Pereira Iglesias, José Luis (ed.). Felipe $V$ de 
Borbón, 1701-1746. Actas del Congreso de San Fernando y Cádiz, 27 de noviembre a 1 de diciembre de 2000. San Fernando-Córdoba: Fundación Municipal de Cultura-Universidad de Córdoba, 2002, pp. 61-90.

Melón JimÉNEZ, Miguel Ángel. «Las fronteras de España en el siglo XVIII: algunas consideraciones». Obradoiro de Historia Moderna, 2010, 19, pp. 161-186.

MELón JiMÉNEZ, Miguel ángel. “Una lima sorda que realmente mina el Estado”. Efectos indeseados de la persecución del contrabando en España durante el siglo XVIII». En ANDúJar CAstillo, Francisco y PONCE Leiva, Pilar (coords.). Debates sobre la corrupción en el mundo ibérico, siglos XVI-XVIII. Alicante: Biblioteca Virtual Miguel de Cervantes, 2018, pp. 643-655.

Merino Navarro, José Patricio. Hacienda y Marina en Francia. Siglo XVIII. Madrid: Fundación Juan March, 1981.

Merino Navarro, José Patricio. La Armada española en el siglo XVIII. Madrid: Fundación Universitaria Española, 1981; reeditado, Madrid: Ediciones 19, 2019.

Merino NavarRo, José Patricio. "Graving Docks in France and Spain Before 1800». Mariner's Mirror, 1985, 71, 1, pp. 35-58.

Merino NaVARro, José Patricio. Las cuentas de la Administración central española, 1750-1820. Madrid: Instituto de Estudios Fiscales, 1987.

Merino NAVARRO, José Patricio. «La città e l'arsenale di El Ferrol nel XVIII secolo». En Concina, E. (a cura di). Arsenali e città nell'Occidente europeo. Roma: NIS, 1987, pp. 175-188.

Merino Navarro, José Patricio. La Hacienda de Carlos IV. Madrid: Rh+ Ediciones, 2014.

ODRIOZOLA OYARBIDE, M. ${ }^{a}$ Lourdes. "La industria naval guipuzcoana y la producción de navíos para el rey (1650-1799)». Boletín de la Real Sociedad Bascongada de los Amigos del País, 1994, 1, pp. 3-41.

Oliva Melgar, José María. Cataluña y el comercio privilegiado con América en el siglo XVIII: la Real Compañia de Comercio de Barcelona a Indias. Barcelona: Publications de la Universitat de Barcelona, 1987.

PARKER, Geoffrey. The Military Revolution. Cambridge: Cambridge U. Press, 1988.

PÉREZ SARRIón, Guillermo. "Gremios, gremios mayores, Cinco Gremios Mayores: Madrid, 1680-1790. Una interpretación y algunas preguntas». En ANGUlo Morales, Alberto y ARAGÓN RUANO, Álvaro (eds.). Recuperando el norte. Empresas, capitales y proyectos atlánticos en la economía imperial hispánica. Bilbao: Universidad del País Vasco, 2016, pp. 19-62.

Peris SÁnchez, Diego; Lucas Martínez, Antonio y Alcalde, Ángel. La fábrica de armas de Toledo. Historia. Ciudad Real: Universidad de Castilla-La Mancha, 1999.

Pulido Bueno, Ignacio. José Patiño. El inicio del gobierno político-económico ilustrado en España. Huelva, 1998.

Quatrefages, René. La Revolución Militar Moderna. El Crisol Españo. Madrid: Ministerio de Defensa, 1996.

RABANAL Yus, Aurora. Las reales fundiciones españolas del siglo XVIII. Madrid: Estado Mayor del Ejército, 1990

RoberTs, Michael. "The Military Revolution». En RoberTs, Michael (ed.). Essays in Swedish History. Londres, pp. 195-225.

Rodríguez Gordillo, José Manuel y Gárate Ojanguren, M. ${ }^{a}$ Montserrat (eds.). El monopolio español de tabacos en el siglo XVIII. Consumos y valores: una perspectiva regional. Madrid: Fundación Altadis, 2007. 
SÁNCHEZ BelÉN, Juan. La política fiscal de Castilla durante el reinado de Carlos II. Madrid: Siglo XXI, 1996.

SÁNCHEZ SANTIRó, Ernest. Corte de Caja. La Real Hacienda de Nueva España y el primer reformismo fiscal de los Borbones (1720-1755). Alcances y contradicciones. México: 2013.

SANZ AYÁn, Carmen. "Administration and Resources for the Mainland War in the First Phases of the War of the Spanish Succession». En Bowen, Huw y González Enciso, Agustín (eds.). Mobilising Resources for War, 2006, pp. 135-158.

SANZ AYÁn, Carmen. "Négoce, culture et sens de l'opportunité dans la construction d'un lignage. Le premier marquis de Santiago pendant la Guerre de Succession». En DuBET, Anne y LuIs, Jean-Philippe (dirs.). Les financiers et la construction de l'État. France, Espagne (XVIIe-XVIIIe siècle). Rennes: Presses Universitaires de Rennes, 2011, pp. 105-124.

SANZ AYÁn, Carmen. "Causas y consecuencias económicas de la Guerra de Sucesión Española». Boletín de la Real Academia de la Historia, 2013, CCX-II, pp. 187-226.

SERRANO ÁLVAREZ, José Manuel. El astillero de La Habana en el siglo XVIII. Madrid: Ministerio de Defensa, 2018.

SOLBES FERRI, Sergio. «Tesorerías de Ejército: estructuras administrativo-contables para la gestión de los recursos fiscales en la España borbónica. Galicia, 1765-1780». Obradoiro de Historia Moderna, 2007, 16, pp. 197-211.

SOlBES FerRI, Sergio. "Contracting and Accounting: Spanish Army Expenditure in Wardrobe and the General Treasury Accounts in Eighteenth Century». En HaRDING, R. y SolbeS FERRI, Sergio (eds.). The Contractor State and its Implications, 1659-1815. Las Palmas de Gran Canaria: Universidad de Las Palmas, 2012, pp. 273-294.

SOLBES FERRI, Sergio. "Campillo y Ensenada. El suministro de vestuario para el ejército durante las campañas de Italia (1741-1748)». Studia Historica. Historia Moderna, 2013, 35, pp. 201-234.

SOLBES FERRI, Sergio. «El control del gasto de la Marina española en las Secretarías de Estado y del Despacho. Los pagos dependientes de la Tesorería General en la primera mitad del siglo XVIII. En BAUDOT, María (editora). El Estado en guerra. Expediciones navales españolas en el siglo XVIII. Madrid: Polifemo, 2014, pp. 147-194.

SOlBES FERRI, Sergio. "Gasto militar y agentes privados. La provisión de uniformes para el ejército español en el siglo XVIII. Tiempos Modernos, 2015, 8, 30, revista electrónica.

STORRS, Christopher. The Fiscal-military State in Eighteenth Century Europe. Farnham: Ashgate, 2008.

'T HART, Marjolein; BRANDOn, Pepijn y TORRES-SánCHEZ, Rafael. «Introduction: maximising revenues, minimising political costs-challenges in the history of public finance of the early modern period", Financial History Review, 2018, 25.1, pp. 1-18.

Tedde de LorCA, Pedro. El Banco de San Carlos (1782-1829). Madrid: Alianza, 1988.

Thompson, I. A. A. War and Government in Habsburg Spain, 1560-1620. Londres: The Athlone Press, 1976.

Tielve García, Natalia (coord.). La Real Fábrica de armas de Trubia: Patrimonio de la industrialización en España. Gijón: CICEES. Centro de Iniciativas Culturales, 2010.

TORREJÓN CHAVES, Juan. «Estructura y organización de la producción en los arsenales de la Marina española del siglo XVIII. Revista de Historia Naval, 2001, 74, pp. 55-82.

TORRES SÁncheZ, Rafael. "Servir al rey más una comisión". Los financieros de la Corona española durante la segunda mitad del siglo XVIII». En Fernández Albaladejo, Pablo 
(coord.). Monarquí, Imperio y pueblos en la España Moderna. Alicante: Universidad de Alicante, 1997, pp. 149-167.

TORRES SÁNCHEZ, Rafael. "Comercio y asientos militares. Hacia la integración comercial del Cantábrico en el siglo XVIII. Cuadernos de Investigación Histórica, 1999, 17, pp. 81-108.

TORRES SÁNCHEZ, Rafael. «Producir o comprar. La demanda de la Corona española de productos industriales en el siglo XVIII». En Ribot García, Luis y De Rosa, Luigi (eds.). Industria y Época Moderna. Madrid: Actas e Istituto Italiano per gli Studi Filosoficci, 2000, pp. 95-131.

TORRES SÁNCHEZ, Rafael. "Cuando las reglas del juego cambian. Mercados y privilegio en el abastecimiento del ejército español en el siglo XVIII. Revista de Historia Moderna. Anales de la Universidad de Alicante, 2002, 20, pp. 487-511.

TORRES SÁNCHEZ, Rafael. "Campomanes y el comerciante y financiero Simón Aragorri». En Mateos Dorado, Dolores (ed.). Campomanes doscientos años después. Oviedo: Universidad de Oviedo, 2003, pp. 709-718.

TORRES SÁNCHEZ, Rafael. «Public Finances and Tobacco in Spain for the American War of Independence». En Bowen, Huw y GonZÁlez EncIso, Agustín (eds.). Mobilising Resources for War, 2006, pp. 191-224.

TORReS SÁNCHEZ, Rafael (ed.). War, State and Development. Fiscal-military States in the Eighteenth Century. Pamplona: Eunsa, 2007.

TORRES SÁNCHEZ, Rafael. "Los navarros en la provisión de víveres de la armada española durante el siglo XVIII. En Volver a la "bora navarra". La contribución navarra a la construcción de la monarquía española en el siglo XVIII. Pamplona: Eunsa, 2010, pp. 213-264.

TORRes SÁnChez, Rafael. La llave de todos los tesoros. La Tesorería General de Carlos III. Madrid: Sílex, 2012.

TORRES SÁNCHEZ, Rafael. El precio de la guerra. El Estado fiscal-militar de Carlos III (1779-1783). Madrid: Marcial Pons, 2013.

TORRES SÁNCHEZ, Rafael. "Administración o asiento. La política estatal de suministros militares en la Monarquía española del siglo XVIII». Studia Historica. Historia Moderna, 2013, 35, pp. 159-199.

TORRES SÁNCHEZ, Rafael. "In the Shadow of Power: Monopolist Entrepreneurs, the State and Spanish Military Victualling in the Eighteenth Century». En FYnN-Paul, J. (ed.). War, entrepreneurs, and the State in Europe and the Mediterranean, 1300-1800. Brill: Leiden, 2014, pp. 260-283.

TORRES SÁNCHEZ, Rafael. Constructing a Fiscal-military State in Eighteenth Century Spain. Basingstoke: Palgrave, 2015.

TORRES SÁNCHEZ, Rafael. Military Entrepreneurs and the Spanish Contractor State in the Egihteenth Century. Oxford: Oxford U. P., 2016.

UzTÁriz, Gerónimo de. Theorica y practica de comercio y de marina. Editado por Gabriel Franco. Madrid: Aguilar, 1968.

Valdez-Bubnov, Iván. Poder naval y modernización del Estado: política de construcción naval española (siglos XVI-XVIII). México: Universidad Autónoma, 2011.

VALDEZ-BuBnOv, Iván. «Shipbuilding administration under the Spanish Habsburg and Bourbon regimes (1590-1834): A comparative perspective», Business History, 2018, 60, 1, pp. $105-125$. 
